\title{
Preparation of Cellulose Nanofiber (CNF) - Montmorillonite (MMT) Nanocomposite via Spray Coating Process
}

\section{Kirubanandan Shanmugam}

Department of Chemical Engineering, Monash University, Australia.

\begin{abstract}
The spray coating process is implemented through the production of smooth Montmorillonite (MMT) Cellulose nanofiber (CNF) composite functioning as a barrier material and base substrate for printed electronics. In this process, the effect of MMT loading into the cellulose nanofiber (CNF) suspension for producing nanocomposite is independent of the operation time. Throughout this investigation, the barrier, surface, and topography of the spray coated nanocomposites were investigated. The MMT content varied from $5 \mathrm{wt} . \%$ to $75 \mathrm{wt} . \%$ in the composites via spraying of $2 \mathrm{wt} \%$ of CNF suspension. Three types of nanocomposites were prepared from cellulose nanofiber with the MMT category of closite $\mathrm{Na++}$, closite $\mathrm{Ca}++$ and closite 116 . By varying the MMT content in the nanocomposite, the spray coating was more productive with the basis weight of nanocomposites ranging from $\sim 70 \mathrm{~g} / \mathrm{m}^{2}$ to $\sim 100 \mathrm{~g} / \mathrm{m}^{2}$ with sheet thickness varying from $\sim 81.7 \mu \mathrm{m}$ to $135.8 \mu \mathrm{m}$ and independent of the operation time which was less than 1 min. The air permeance and water vapour permeability of the spray coated nanocomposites were investigated to confirm the green materials was infact barrier material. Aggregation of MMT clays on a further increase of MMT in nanocomposite resulted in the elevation of WVP. The composite has two unique surfaces, namely rough and smooth surfaces from metal side. Scanning electron microscopy (SEM) reveals the distribution of MMT on the surface, compactness and smoothness of the composite. The composites are flexible, demonstrate good uniformity and pigmentation as a result of an increase in MMT loading.Considering the barrier performance and surface roughness of nanocomposites, it can be used as packaging materials and as a base substrate for printed electronics. In comparsion, spray coating is a more efficient process for producing sustainable nanocomposites as alternative for synthetic plastics.

(C) $2021 \cdot$ INScienceIN. All rights reserved
\end{abstract}

ARTICLE HISTORY

Received 27-02-2021

Revised 08-04-2021

Accepted 09-04-2021

Published 16-06-2021

\section{KEYWORDS}

Spray coating,

Cellulose nanofibre (CNF)

Montmorillonite (MMT)

Nanocomposites

Water vapour

permeability

Surface Roughness

\section{Introduction}

Synthetic plastics are extensively used throughout the development of functional materials such as barrier layers on cellulosic substrates, packaging films and substrates for printed electronics. However, they have poor recyclability, biodegradability and their waste products are highly detrimental for the environment. To overcome this problem, cellulose fibre-based materials are used in the construction of various functional materials including barrier materials. Cellulosic macrofibre products such as paper and paperboard are equally as predominant as synthetic plastic materials. It is biodegradable and therefore ensure safety for the environment. The hydrophilic nature of cellulose macro fibres limits the specific application in various fields. In packaging, cellulose fibre products are a recyclable and biodegradable material. Due to the presence of large pores and high affinity towards water and its vapour, this results in poor water vapour and oxygen barrier performance. To note, these materials are not for fit for packaging under medium and high humidity environment. To mitigate these limitations, the cellulose fibre products are often associated with plastics, wax and/or aluminium, with the intention of enhancing their barrier properties. However, these materials suffer from serious environmental issues, such as difficultly and in efficiency of recycling. Recently, cellulose nanofibers such as nanocellulose (NC), Microfibrillated cellulose (MFC) have been proven to efficiently play a predominant role in material development due to its outstanding properties, primarily being good mechanical strength, biodegrdability, larger surface area, etc, [1,2]. Cellulose nanofiber is made though the process of breaking down cellulose macrofibres into nanofibers with diameters ranging from $5-100 \mathrm{~nm}$ and is a building block for the development of novel and high-performance cellulosebased functional materials. It is a recyclable, compostable and biodegradable alternative to synthetic plastics $[1,2]$. It is mainly used as a coating for materials to enhance the barrier properties of a base sheet and the fabrication of cellulose nanofiber films and laminates on the paper. Cellulose nanofibers have good water vapour permeability and oxygen permeability, however limitations in their barrier performance occur under environments with medium and high humidity. To overcome this limitation, Montmorillonite (MMT) can be incorporated into the cellulose nanofiber network, so MMT would increase tortuous pathways for water vapour and oxygen. As a result, the barrier performance of cellulose nanofiberMMT composite would be enhanced.

Recently, free-standing cellulose nanofibrils composite film are used in the development of high strength barrier materials [3]. The composite film produced via vacuum filtration has excellent mechanical and barrier properties. Vacuum filtration has many constraints for preparation of cellulose nanofiber nanocomposite films as it requires 30 mins to 24 hours of filtration time [4-6]. Recently, this technique has been reported as a fast method for pure CNF film, and to reduce the preparation time from 30 minsto 10 mins [7]. The addition of MMT in the cellulose nanofibre and high homogenization of cellulose nanofibre suspension 
consumes more time for film formation in vaccum filtration and especially in the water draining step in the vaccum filtration process. However, this is still high enough to make scale-up difficult [8]. The limitations in this method are peeling the film from the filter surface and high dewatering time when the MMT concentration is increased during the CNF suspension. Apart from this method, casting, layer by layer assembly and spin coatings are the laboratory scale methods for developing CNF-MMT composites.

Existing techniques to prepare CNF -MMT composites are a conventionaly time-consuming process and expensive. Therefore, another cost-effective and readily implementable methodologies are required to achieve freestanding CNF-MMT composite films. Therefore, the rapid and flexible method for developing composite film is required.

Spraying cellulose nanofibers with inorganics is an alternative technique to construct composite films that have been used to produce continuous self-standing films by spraying on to a fabric or composite laminates and a base sheet $[5,6]$. Spraying has notable advantages such as the formation of the homogeneous layer and contour coating on the substrates [5]. The range of basis weight achievable with spraying yields much higher than films via vacuum filtration. Spraying can also be performed at a higher initial solid content compared to vacuum filtration, thus reducing the amount of water in subsequent drainage. Spraying has so far, not been used to make discrete sheets for laboratory investigations, or for small scale products. As per the process intensification approach, the application of spray coating to prepare nanocomposites and how spray coating competes with vacuum filtration has not yet been investigated. The spraying may potentially provide a platform for the development of self-standing films/sheets/nanocomposite.

Recently, a rapid spray coating method has been implemented to produce composites such as graphite carbon black-micro fibrillated cellulose as an electrode [6] and $\mathrm{SiO}_{2}$-microfibrillated cellulose nanopaper. It was reported an operation time of fewer than 30 minutes and $\mathrm{SiO}_{2}$ can be varied from 0 to $33 \mathrm{wt} \%$ into the suspension resulting tailorable properties of composite [9]. In this method, they replaced vacuum filtration with spray coating but followed the conventional process including transfering the composite with blotter and dewatering of the composite by vacuum and then peeling the film off after drying [9]. The developing nanocomposite and tailoring its properties by the addition of specific nanoparticles/nanofillers in the nanocellulose/cellulose nanofiber suspension via spraying is a novel process. Similar trend with cellulose nanofiber film can be seen that the operation time independent of cellulose nanofiber concentration and nanoclay loading in the suspension.

This paper does focus on spray coating as a novel method to prepare free-standing CNF-MMT composites. This research investigates the barrier properties and surface roughness of the composites.

\section{Experimental \\ Materials and methods \\ CelluloseNanofiber}

The nomenclature for cellulose nanofiber has not been reported consistently as per the reported scientific publication. Cellulose nanofiber is also referred to as micro-fibrillated cellulose (MFC), cellulose nano-fibrils, cellulose microfibrils, nano-fibrillated cellulose (NFC) or Nanocellulose (NC). Throughout this paper, the generic term for the cellulose nanofiber (CNF) was used. The CNF was supplied from DAICEL Chemical Industries Limited Japan (Celish KY-100S) at a $25 \%$ solids content. DAICEL NC (Celish KY-100S) has cellulose nanofibrils with an average diameter of $\sim 70 \mathrm{~nm}$ [10] with a wide distribution of fibre diameter, a mean length of fibre around $8 \mu \mathrm{m}$ and an average aspect ratio of $142 \pm 28$ [10].

\section{Montmorillonite (MMT)}

Closite $\mathrm{Na}++$, Closite $\mathrm{Ca}++$, Closite 116 are nano clay montmorillonite (MMT) powder provided by BYK Additives and Instruments, Germany through IMCD Australia Limited, Mulgrave VIC 3170, Australia. The dry particle size of MMT is $<25 \mu \mathrm{m}\left(\mathrm{d}_{50}\right)$ and has a packed bulk density of $568 \mathrm{~g} / \mathrm{l}$ and density of $2.86 \mathrm{~g} / \mathrm{cm}^{3}$ with X-Ray results confirming do01 of $1.17 \mathrm{~nm}$.

\section{Preparation of Cellulose Nanofiber-MMT suspension}

A cellulose nanofiber suspension of $2 \mathrm{wt} \%$ was prepared through the addition of $80 \mathrm{~g}$ of DAICEL KY100S into the $920 \mathrm{~g}$ of deionised water and was disintegrated for 15,000 revolutions at $3000 \mathrm{rpm}$, with the MMT addition is based on cellulose nanofiber content in the cellulose nanofiber solid from the DIACEL company and was varied at $5 \mathrm{wt} \%$, 10 wt.\%, 20 wt.\% ,30wt.\%, 50\% and 75\%.The known quantity of MMT was dispersed in double distilled water with intensive agitation. The given quantity of cellulose nanofiber was added into the MMT solution to make suspension via disintegrating in High-speed disintegrator.

\section{Spraying of Cellulose nanofiber - MMT suspension}

The experimental setup for a laboratory scale spray coating system with experimental conditions is displayed in Fig. 1. The CNF-MMT composite film was prepared according to the reported method [11] by spraying onto a stainless-steel plate on a moving conveyor at a fixed velocity of $1.25 \pm 0.25$ $\mathrm{cm} / \mathrm{sec}$ using a Professional Wagner spray system (Model number 117) at a pressure of 200 bar. The type 517 spray tip used in the spray system produced an elliptical spray jet and the spray jet angle and beam width were $50^{\circ}$ and 22.5 $\mathrm{cm}$, respectively. The spray distance was $30.0 \pm 1.0 \mathrm{~cm}$ from the spray nozzle to the circular/square steel plate. During the spraying, the pressure driven spray system was run for 30 seconds before forming the first film, thus the system reaches an equilibrium. After spraying, the film on the plate was dried under restraint at the edges for at least 24 hours before it was readily peeled of from the stainless-steel plate [12].

\section{Characterization of Freestanding Nanocomposite}

All spray coated nanocomposites were conditioned at $23^{\circ} \mathrm{C}$ and $50 \% \mathrm{RH}$ for 24 hours prior to further testing.The thickness of the spray-coated nanocomposites were determined using a Thickness Tester Type 21 from Lorentzen \& Wettre AB, Stockholm, Sweden. The thickness was measured for at least 25 points on each nanocomposite film and were averaged. The thickness of NC film was measured according to the Australian/New Zealand standard method 426.

\section{Air permeance of Nanocomposite}

The air permeance of nanocomposites were measured with an L\&W air permeance tester with an operating range from 0.003 to $100 \mu \mathrm{m} / \mathrm{Pa}$.S. The mean value of air permeance evaluated from 3 different areas of each CNF and composite 

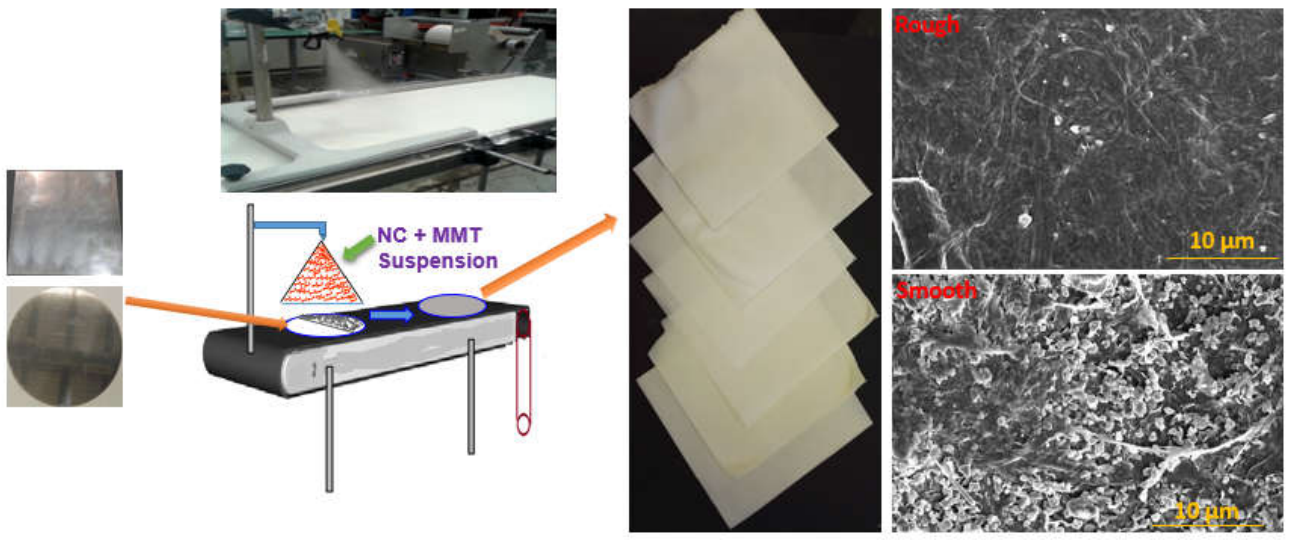

$\begin{array}{ll}\text { Stainless } & \text { Conveyor and Professional } \\ \text { Steel } & \text { Spray system } \\ \text { Plate } & \end{array}$

Nanocomposites

Figure 1: Spray Coating Experimental Set up for Preparation of CNF-MMT nanocomposite

film were reported. The Technical Association of the Pulp and Paper Industry (TAPPI) standard of T 460 was used to measure the air permeance of the films.

\section{Water vapour permeability of Nanocomposite}

Water vapour permeability (WVP) was evaluated according to the ASTM standard (E96/E96M-05) method using anhydrous calcium chloride. Prior to testing, CNF film was dried for 24 hours at a temperature of $105^{\circ} \mathrm{C}$ in an air oven. $40 \mathrm{~g}$ of dried anhydrous $\mathrm{CaCl}_{2}$ was taken into the cups and CNF films were covered with these cups. The increase in weight of the cups is caused by the absorption of water vapour with $\mathrm{CaCl}_{2}$ in the cups through CNF- MMT Composite film. A test samplewas weighed for each standard interval of time. The variation in weight of the cups with time was noted and the slope of the line between weight and time was determined for WVTR. The water vapour transmission rateswere carried out at $23^{\circ} \mathrm{C}$ at $50 \%$ RelativeHumidity [13]. The water vapour transmission rate (WVTR) of CNF -MMT Composite film is normalised with the thickness of the composite film and converted into WVP. The mean value of three parallel tests of each CNF MMT Composite was reported.

Surface and Cross-sectional Investigation of Nanocomposites The surface (both rough and smooth sides of the composite) as well as cross-sections of the nanocomposite is performed by SEM FEI Magellan 400. For the crosssectional investigation, the samples were soaked in liquid Nitrogen and a fracture on the samples were performed with a tweezer and then the samples were mounted onto a metal sample holder and coated with a thin layer of Iridium prior to Imaging. The SEM micrographs were taken at magnification ranging from $500 \mathrm{X}$ to $50000 \mathrm{X}$.

Surface Roughness of Spray Coated Nanocomposites The surface roughness of both sides of the film at nanoscale were evaluated through optical profilometry. The size of each specimen's area from the smooth composite films was $100 \mathrm{~mm}^{2}$ selected from uniform films lacking surface defects and pinholes. The film peeled from the substrate was the smooth surface of the composite film and the side exposed to air was the rough side. An optical profiler (Olympus OLS 5000 Laser Confocal Microscope) was used to evaluate the aerial roughness of a $259 \mu \mathrm{m} \times 259 \mu \mathrm{m}$ area of the CNF-MMT films of both the rough and smooth sides. The average aerial roughness, Sa, and root mean square (RMS) roughness, Sq of both sides of CNF -MMT films were evaluated from the instrument software. Six films were taken for measuring the roughness parameters. The minimum of six locations per each film were considered for each evaluation of aerial roughness.

\section{Results and Discussion}

Flexible, Foldable and Uniform MMT-CNF composites via spray coating were developed as shown in Fig. 2. The properties of composites were tailored via varying MMT content from 0 to $75 \mathrm{wt} . \%$ in $2 \%$ wt. CNF suspension. The air and water vapour permeability (WVP) properties of composites via spraying were evaluated for each type of composite film. Spray coated cellulose nanofiber MMT composites were good uniformity evaluated via thickness measurement. The composites were increasingly yellowish in colour in the Closite $\mathrm{Na}++$ MMT composite, reddish in the Closite Ca++ MMT composite, light grey in the Closite 116 MMT composite due to the increased MMT content from $5 \%$ to 75 wt.\%. This is due to the absorption spectra of MMT in the nanocomposites, which is similarly observed by [14] and [15]. The smooth and coloured composite as a finishing quality is achieved by spray coating and adjusting the MMT loading in CNF suspension.

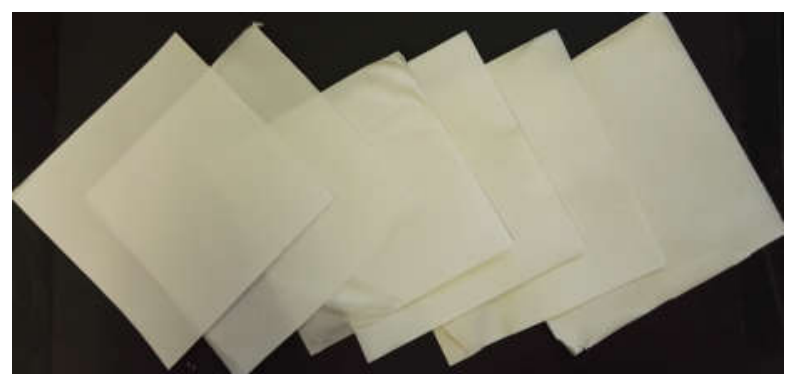

Figure 2: Spray Coated Nanocomposites prepared via spraying cellulose nanofiber -MMT produced from spraying of CNF -Closite $\mathrm{Na++}$ suspension on the stainless-steel plate.The size of cellulose nanofiber composite is $220 \mathrm{~mm} \times 220 \mathrm{~mm}$ and thickness vary from $\sim 81.7 \mu \mathrm{m}$ to $135.8 \mu \mathrm{m}$. The basis weight of the film varies from $\sim 70$ $\mathrm{g} / \mathrm{m}^{2}$ to $\sim 100 \mathrm{~g} / \mathrm{m}^{2}$. 
Surface Morphology and Topography of Spray Coated

Nanocomposites

Figure 3 shows the rough surface of the pure cellulose nanofiber film and 30 wt. $\%$ and 10 wt. \% MMT-CNF composites prepared via spray coating. The images reveal the presence of MMT platelets and its /even distribution throughout the rough surface of spray coated nanocomposite. The MMT particles are present on the surface of nanocomposite which is notably embedded and impregnated in the cellulose fibrous network. The size of MMT varies from 300 to $1000 \mathrm{~nm}$ and can be said to be impregnated into the pore of cellulose nanofiber.
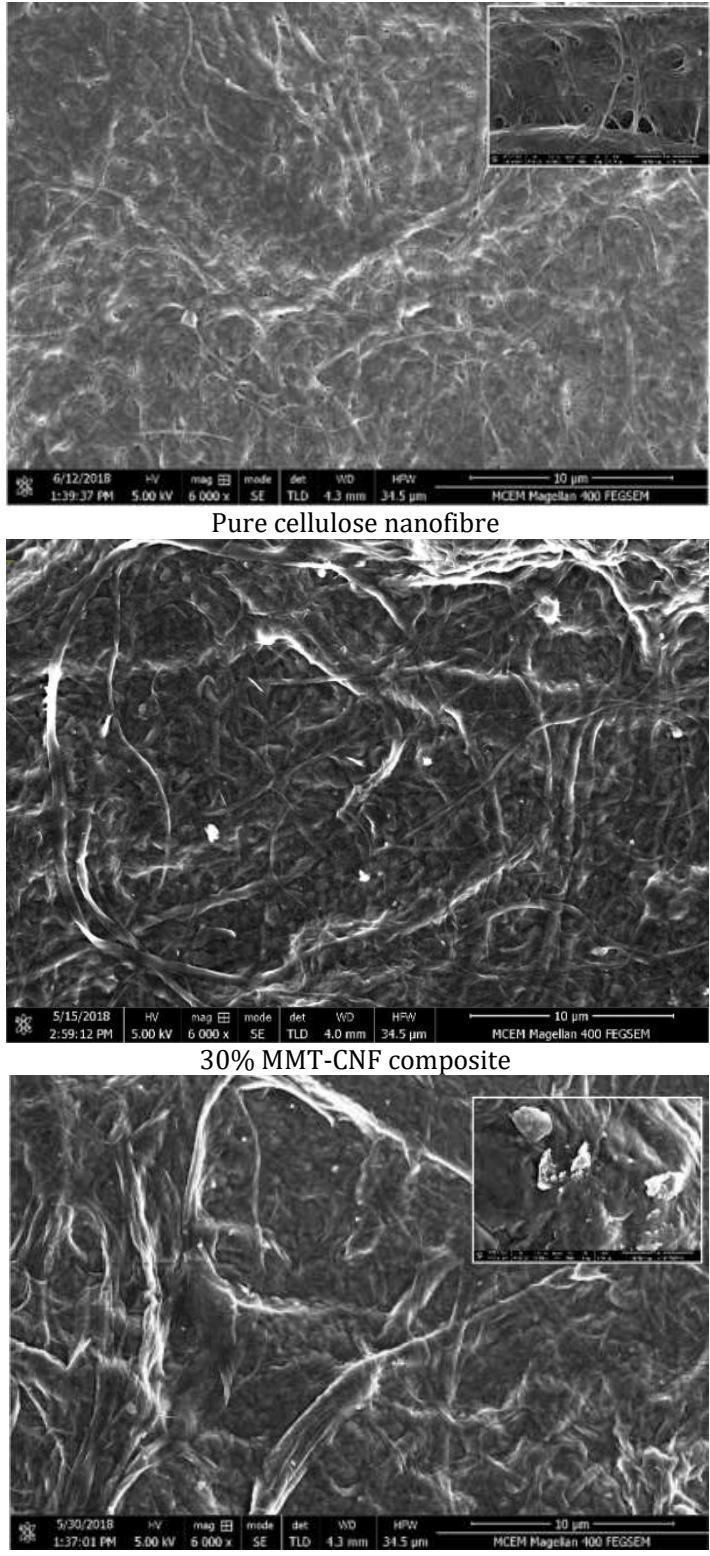

10\% MMT-CNF composite

Figure 3: Spray coated CNF-MMT Composite (Rough Side) and CNF film (Rough side). The macro scale surface roughness of the rough side of Spray coated CNF-MMT composite varies from

$10.5 \mu \mathrm{m}$ to $11 \mu \mathrm{m}$ evaluated from Parker Surface Print Instrument and the nanoscale surface roughness is determined to be $2945 \pm 277 \mathrm{~nm}$ on the rough side via the optical profilometry.

Figure 4 reveals the smooth side of composites and confirming the distribution of MMT in the composites. MMT was stacked in the spray coated composites. This stacking of MMT affected the barrier performance of the composites. The spraying CNF-MMT suspension on the stainless steel produces the smooth film by replicating the smoothness of stainless-steel plate.
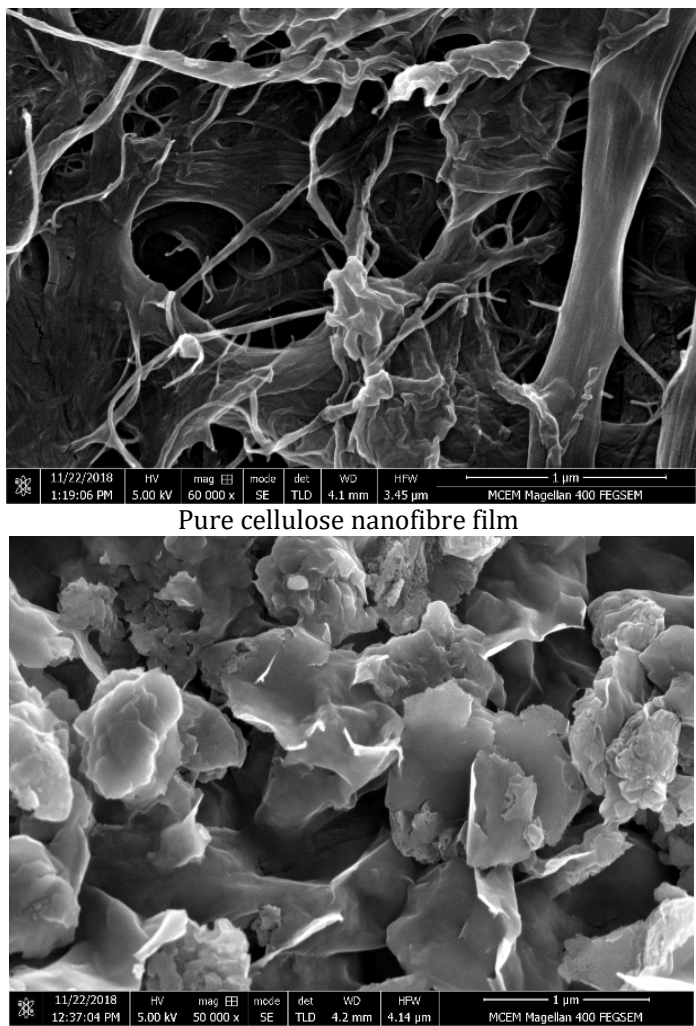

$30 \%$ MMT-CNF composite

Figure 4: Smooth side of composites via spray coating
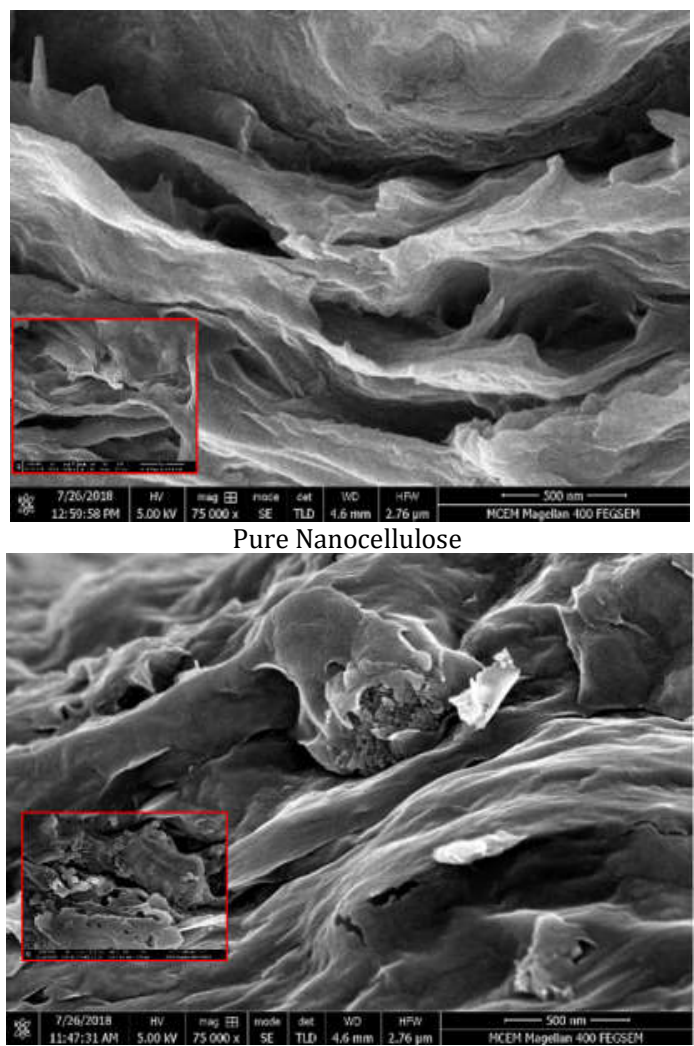

30\% MMT-nanocellulose composite

Figure 5: Cross-sectional investigation of the spray coated nanocomposite 
Cross-sectional View of Spray Coated Nanocomposites

Figure 5 displays the SEM micrograph on the crosssectional view of the MMT-CNF composite. The aggregation of MMT as stacks was observed on the edges of the spray coated nanocomposites. The average diameter of CNF fibrils is $70 \mathrm{~nm}$ with a wide distribution of fibre diameter, a mean length of fibre around $8 \mu \mathrm{m}$ and an average aspect ratio of $142 \pm 28$. The size of MMT particles varied from 300 to $1000 \mathrm{~nm}$ in length. The MMT platelets were exfoliated between cellulose nanofibrils due to their large aspect ratio.

\section{Barrier Performance of Spray Coated Nanocomposite}

The air permeance of all spray coated nanocomposite was evaluated to be less than $0.003 \mu \mathrm{m} / \mathrm{Pa}$.S (Fig. 6). This value concluded that the spray coated composite would be a sustainable barrier material against air and oxygen. In addition to this, the effect of metallic ions in the MMT such as $\mathrm{Na}++$ and $\mathrm{Ca}++$ does not play role in controlling the barrier performance against air. The MMT loading in the nanocomposite does not depends on the air permeance of the composite. The spraying cellulose nanofiber -MMT suspension on stainless steel plates produces a compact structure of nanocomposite giving an impermeable composite film as barrier against air.

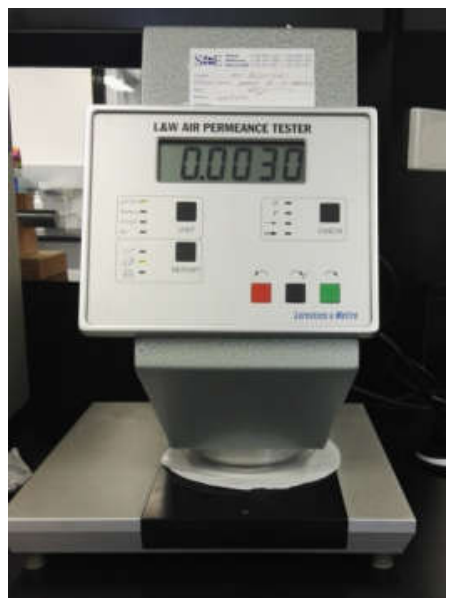

Figure 6: Measurement of Air permeance of spray coated nanocomposite

Water vapour permeability of Spray Coated Nanocomposite

Figure 7 shows the water vapour permeability of spray coated nanocomposites prepared from various MMT such as closite $\mathrm{Ca}^{++}$, closite $\mathrm{Na}^{++}$and closite 116 . The effect of the addition of MMT at various levels were demonstrated also in this figure. The pattern on increase WVP with MMT content was same for three types of composites.The WVP of spray coated nanocomposites via spray coating increased as the MMT concentration increased, reaching $3.3 \pm 0.07 \times 10^{-11} \mathrm{~g} /$ Pa.s.m at $30 \%$ MMT (Closite $\mathrm{Na}^{++}$) loading and $5.0 \times 10^{-11} \mathrm{~g} /$ Pa.s.m at $75 \%$ MMT (Closite $\mathrm{Na}^{++}$) loading from a value of $2.5 \pm 0.12 \times 10^{-11} \mathrm{~g} /$ Pa.s.m for spray coated pure CNF/ NC film. For sprayed composites, the WVP of the composite initially decreased for $5 \mathrm{wt} . \%$ loading compared to pure CNF films and beyond.

The elevation of WVP of the composite was due to increase of MMT loading.The WVP of spray coated composites was shown to yield a higher WVP when produced by this method, especially when compared to similar films by method of vacuum filtration [14]. The reason for this elevation in WVP for spray coated composites was the aggregation and stacking of MMT within the cellulose nanofibers, which is more dominant at a higher loading for nanocomposites. The effect of metal ion in MMT on the barrier performance of the nanocomposite remains obscure. There was an influence of metal ion on the barrier performance of the composite and mechanism of influence to be investigated. The breaking of the MMT aggregates and cellulose nanofiber via high pressure homogenization and then fabricate composite via spraying process. Then it can improve the barrier performance of the CNF-MMT composite.

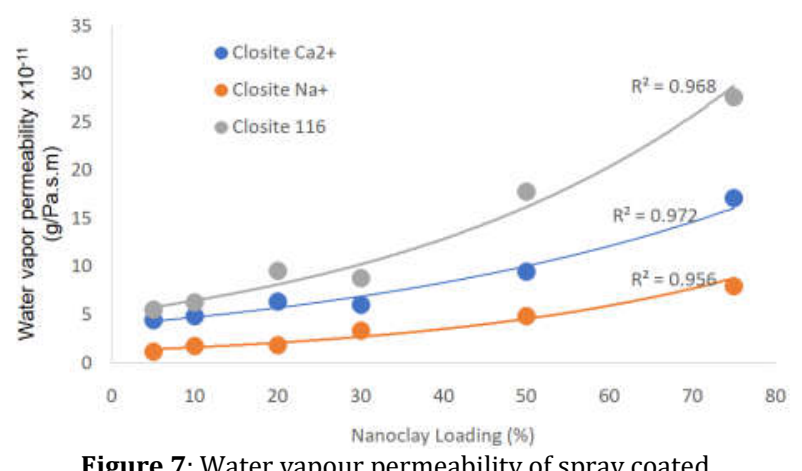

Figure 7: Water vapour permeability of spray coated nanocomposites

Surface Roughness of Spray Coated Nanocomposites The rough side of the MMT composite is highly porous in contrast to its smooth surface. The macro scale roughness of the nanocomposite evaluated via parker print surface instrument are found to be $10.5 \mu \mathrm{m}$ to $11 \mu \mathrm{m}$ on the rough side and $3.5 \mu \mathrm{m}$ on the smooth side.

\section{Optical Profilometry Investigation of Nanocomposite}

The surface roughness of the spray coated nanocomposite at nanoscale were evaluated by method of optical profilometry. The aerial surface roughness at the nanoscale of $30 \mathrm{wt} . \%$ the MMT composite was evaluated through optical profiler are found to be $2945 \pm 277 \mathrm{~nm}$ on rough side and $1412 \pm 37 \mathrm{~nm}$ on the rough side of the composite and $1600 \pm 554 \mathrm{~nm}$ and $575 \pm 20 \mathrm{~nm}$ on the smooth side of the nanocomposite. In comparison to the aerial roughness of the pure cellulose nanofiber film and the film from highpressure homogenization are $3937 \pm 1213 \mathrm{~nm}$ and $1893 \mathrm{~nm}$ on the rough side and $1622 \mathrm{~nm}$ and 1257 on the smooth side, thus concluding that the addition of MMT into the cellulose nanofiber suspension will not change the surface properties of the nanocomposite, and thus does not have an impact on large magnification.

\section{Discussion}

Currently, the most common method for the fabrication of MMT/CNF composites is solvent casting, hot pressing, and vacuum filtration. Apart from these methods, resin impregnation, film stacking is also exampling of laboratoryscale methods for fabricating high barrier performance nanocomposites. These have several limitations like difficult to achive a larger area of a film with a substantial thickness. Equally, the addition of MMT into the CNF suspension causes increase in the drying time in the solvent, being roughly 3 to 4 days. In the process of vaccum filtration, an increase in dewatering time with an increase in loading of MMT can take roughly to 30 mins to 24 hours.Moreover, peeling the nanocomposite from the filter surface is a quite challenging task in vacuum 
filtration, as it bears the risk of causing surface destruction on the nanocomposite film.

The research objective is the production of a nanocomposite through rapid film formation via spraying. The process of spraying a MMT- CNF suspension on a polished metal surface to produce a nanocomposite with two distinct surfaces is a novel process which will ensure the good density of the composites, via controlling their thickness and basis weight of the composite. This method has a minimal operation time of less than 1 minute [16]. In the spraying process, addition of MMT in the CNF suspension does not affect the time consumption for the film formation and is significantly lower when compared to other conventional methods. All spray coated nanocompositesfilms demonstrate adequate strength and are flexible, with a high standard of surface finish resulting with being rough on its free side and smooth on its stainless-steel side.

Contrasted with vacuum filtration, spray coating is a flexible process to tailor the properties of the nanocomposite with no effects on the addition of nanoclay in the spraying process. The $2 \mathrm{wt} . \%$ CNF with MMT loading varying from $5 \mathrm{wt} . \%$ to $75 \mathrm{wt} . \%$ forms fine droplets from the spray jet to form the composites onto the stainless steel plate without any interuptions in the spray patterns and spray jet. The advantages of spraying with varying nanofillers are its simplicity in film formation, rapidity and achieving the tailorable properties of composites with minimal operation time.

\section{Barrier Performance of spray coated nanocomposites}

The air permeance of all spray coated nanocomposites is $<$ $0.003 \mu \mathrm{m} / \mathrm{Pa}$.S, which confirms a good barrier performance against air. This value within the limitation of the instrument informs that it should be good packaging material and effect of MMT addition into CNF suspension on air permeance is not able to be predicted by the instrument.

Water vapour permeability of the nanocomposites is usually controlled by the structure, content and orientation of MMT in the cellulose nanofibrous matrix. The SEM micrograph proved the good distribution and wide scattering of MMT particles on the surface and interior of spray coated nanocomposites producing a tortuous path, resulting in a lower permeation of water vapour across the composites.

At a high loading of MMT above 5 wt.\% in unhomogenized composites, the elevation of WVP with MMT loading could be due to the hydrophilic nature of MMT, but not due to obtaining a tortuous path because of its large nanofibrils aspect ratio. In other words, the aggregation and stacking of MMT in nanocomposites might be a valid reason for elevating WVP with MMT loading 5 wt. $\%$ in unhomogenized composites.

On the other hand, composites prepared by method of vacuum filtration conveyed similar behaviours for both types of composites. Sodium MMT (montmorillonite) could swell and absorb 5 times more water than its original weight. MMT is uniform broad and in the form of flat platelet, with an exceptionally high surface area of 600 to $800 \mathrm{~m}^{2} / \mathrm{g}$. As a result, Sodium MMT can be played as an ideal filler for enhancing barrier performance of the composite. Furthermore, the hydraulic conductivity of a dense, low porous hydrated bentonite MMT platelet is $1 \mathrm{x}$ $10^{-9} \mathrm{~cm} / \mathrm{sec}$. Thus, MMT Bentonite can be used as nanofillers for lowering the water vapour permeability of CNF [17].
Structure of Spray Coated Nanocomposite

MMT-nanocellulose composites exist primarily in three structural forms being, phase separated, intercalated, and exfoliated [18]. A phase separated structure in the composite confirms the tactoid structure, usually formed in the conventional composites or micro composites where the polymer and clay tactoids were immiscible each other, which forms in the agglomeration of the clay particles in the fibrous matrix resulting in poor properties of the composites [19]. Nanocomposites with an intercalated structure shows the intercalation of layered clays between cellulose fibrils or polymers. In other words, cellulose nanofibrils or polymer chain penetrated into the layered silicates/ clays result in a well organized multilayered structure with alternative and repeated fibre or polymer/clay layers for a few nanometers. The exfoliated nanocomposites show the well-delaminated clay layers being randomly distributed and dispersed into the fibrous or polymer matrix. Consequently, the funtionality and properties of nanocomposites rely on the augmented interaction between clays and polymers or cellulose nanofibrils [20].

\section{Elevation of WVP in Composites}

WVP of composite via spray coating decreased at a $5 \mathrm{wt} . \%$ MMT loading in the cellulose nanofibre's supsension. The MMT platelet's with the largest dimension were arranged and siginficantly organized in the fibrous matrix, resulting a tortuous path in the diffusion pathway reducing WVP.Beyond 5 wt.\% MMT loading, WVP of the composities incresed again with MMT loading upto $75 \%$ wt of MMT . The composities absorb water vapor at higher loading of MMT due to its aggregation, thus allowing the opening of new pores into the struture of unhomogenized composites. This communicates how permeability is one of the most predominant mechanisms in the process of transporting water vapour $(\mathrm{WV})$ into the nancomposities.

The stacking or aggregation of MMT in the nanocomposites is the most common problem and a challenging task in engineering the water vapour permeability of the nanocomposites. This is due to how the dispersion of MMT in the cellulose nanofibre suspension is performed by highpressure homogenization where the cellulose nanofiber suspension with MMT is mixed together with higher intensity before the spraying of suspension on the stainless steel plate to make nanocomposites sheets. Furthermore, homogenization provides fibril into very fine cellulose nanofibrils at a very reduced dimension and thus clay platelets are integrated into the fibrils to form an intercalated structure of composite. The WVP of this composite is quite low, being $1.37 \times 10^{-11} \mathrm{~g} / \mathrm{Pa} . S . m$. Notably, The WVP of $20 \mathrm{Wt} \%$ composite with a high pressure homoginization step is evalauted to be $8.3^{*} 10^{-12} \mathrm{~g} / \mathrm{Pa}$.S.m and these values are quite comparable with synthetic polymers and synthetic nanocomposites. The comparison on the spray coated nanocomposite with other synthetic polymers and nanocomposites are tabulated in Figure 08. At higher MMT loading in the composites, Aggregation of clay platelets is a critical problem, as the processing of suspension of MMT into a nanocomposite would effectively effect its properties, specifically the properties of it's barrier performance and strength of the nanocomposites. The critical parameter used to prepare the MMT-cellulose nanofiber suspensions are shear rate and mixing time. It can be concluded that if the prepared suspension was not processed fast into nanocomposites via spray coating, then as a consequence, the MMTs in the nanocellulose 
suspension would cause the restacking of the MMT, thus resulting in the formation of large aggregates [21] which would be caused by electrostatic and Vanderwall forces [22].

\section{Comparision of Spray Coating With Vaccum Filtration}

In terms of contrasting the methods of spray coating and vaccum filtration, spray coating is more efficient, as spraying high CNF concentrations, results in an independent operation time usually averaging than 1 minute. For example, 0.5 wt.\% CNF suspension requires filtration, the water and CNF ratio is 199:1. In comparison to the ratio for spraying of $2.6 \mathrm{Wt} . \% \mathrm{CNF}+\mathrm{MMT}$ suspension is 97.4:2.6. This demonstrates how vaccum filtration requires a high dewatering time to drain $162 \mathrm{Kg}$ of water. Whereas spraying is a superior alternative and consumes less water through utilizing high CNF concentration and the time independent scalable process for composite fabrication.

Comparison of WVP of Spray coated Nanocomposite with Synthetic Polymers

The WVP of spray coated nanocomposite (SC Nanocomposite) is comparable with composites prepared via the vacuum filtration method (VF Nanocomposite) and other synthetic plastics (Fig. 8). The elevation of WVP in SC Nanocomposite was due to the stacking and aggregation of MMT platelets in the composite. The high-pressure homogenization of cellulose nano fibre with MMT results in the breaking of MMT aggregates and cellulose nanofibers into the fibre mean diameter of $20 \mathrm{~nm}$. As a result, the composites were fabricated via either spray coating or vacuum filtration has the lowest water vapour permeability than the composite fabricated without homogenization. In addition to this, the cellulose nanofibers substrates prepared via either spray coating or vacuum filtration have comparable WVP's to synthetic plastics.

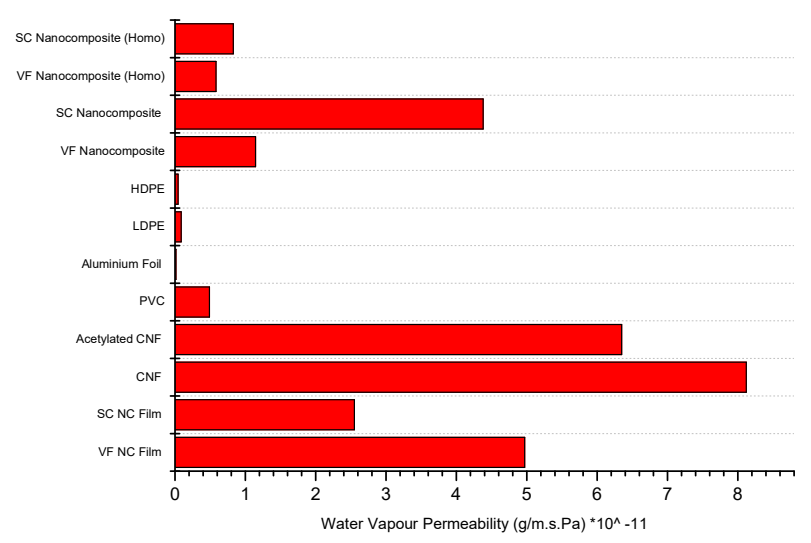

Figure 8: Comparison of WVP of Spray coated Nanocomposite with synthetic polymers

\section{Smooth Surface of CNF-MMT composite}

Spraying of CNF-MMT suspension on the polished stainless-steel plate results in the smooth side of the composite being peeled from its metal side. The surface roughness of the composite on the smooth side was evaluated as being $575 \pm 20 \mathrm{~nm}$ via optical profilometry and $3.5 \mu \mathrm{m}$ via parker print surface instrument. Both the macro scale and nanoscale roughness of the smooth side of the composite confirms it as being a sustainable alternative for synthetic plastics used in the printed electronics industry.
The lowest surface roughness of cellulose nanofiber achieved so far in printed electronic applications was reported as being in the range between $310 \mathrm{~nm}$ and 470 $\mathrm{nm}$ [23]. The surface roughness of synthetic plastics used in the printed electronics was $400 \mathrm{~nm}$ for fabricating electronic circuits on the plastic substrates.

\section{Comparison with other methods for preparing the nanocomposite}

Table 1 gives the comparison of WVP of CNF -MMT composite prepared from various methods.This comparison notifies various processing methodology affecting water vapour permeability of the composites. The developed spray coating process produced potential CNF MMT composites which has the lowest WVP values when comparing with the composites from various methods.

\section{Method on Improving the barrier performance of the composites}

The barrier performance of the nanocomposite can be improved through the fibrillation of a cellulose nanofiber by method of high-pressure homogenization. High pressure homogenization of CNF reduces the fibre size down to 20 $\mathrm{nm}$ and breaks the MMT stacks. These stacks forms aggregates in the suspension and affects the barrier performance of the composite. As a result, the composites prepared via spraying of homogenized CNF-MMT suspension have an excellent barrier performance and are highly comparable to synthetic plastics [24] [14]. The primary predominant factor controlling the surface roughness of the CNF film substrates are its fibril size in CNF film substrates and fibre friction. Fibril size in CNF film substrates can be reduced via high pressure homogenization and fibre friction can be reduced via the addition of polymers such as carboxy methyl cellulose (CMC) during CNF suspension. Therefore, the surface roughness of the film via the spraying of a homogenized CNF suspension with or without CMC would be reduced [25].

\section{Conclusions}

To summarize, a rapid process of spray coating was used to develop a high barrier performance of CNF- MMTnanocomposites with smoothness replicated from the base surface polished stainless steel side. Firstly, these composites demonstrate low water vapour permeability, being nearly comparable to their corresponding films prepared via vacuum filtration. Secondly, the air permeance of spray coated composites is below 0.003 $\mu \mathrm{m} /$ Pa.s, confirming effective alternative packaging materials for synthetic plastics. This valuable quality of air permeance confirms the impermeability of the nancomposite films. Equally, a variance in the MMT Load resulted in no effect on the spraying process, which required an operation time of less than 1 minute. The SEM micrograph reveals that the MMT is well distributed on the surface of both composites and a cross-sectional SEM micrograph confirms the aggregation of MMT in nanocomposite. MMT platelets were aggregated and stacked in both composites at high loading of MMT, resulting in elevating WVP. This investigation confirms spray coating is a rapid, flexible and scalable process which tailors to the properties of nanocomposites with varying MMT loading, and how spray coating can efficiently manufacture a flexible and strong nanocomposite with high-performance barrier properties, especially with a low 
Table 1: Water vapour permeability of CNF-MMT nanocomposites from various methods

\begin{tabular}{|c|c|c|c|c|}
\hline Composite type & $\begin{array}{c}\text { Clay } \\
\text { compositio } \\
\mathrm{n} \text { in the } \\
\text { total } \\
\text { composite }\end{array}$ & Production process & $\begin{array}{l}\text { Temperature } \\
\text { \& Relative } \\
\text { humidity }\end{array}$ & $\underset{\left.\mathrm{KPa}^{-1}\right)}{\text { WVP }}$ (g um $^{-2}$ day $^{-1}$ \\
\hline $\begin{array}{l}\text { Cellulose nanofiber - MMT (Closite } \\
\text { (Na++) Composite }\end{array}$ & $5 \%$ & $\begin{array}{l}\text { Spray coating } \\
\text { Current Method }\end{array}$ & $23^{\circ} \mathrm{C}, 50 \%$ & 1.175 \\
\hline $\begin{array}{c}\text { Cellulose nanofiber - MMT (Closite } \\
\text { Ca++_) } \\
\text { Composite }\end{array}$ & $5 \%$ & $\begin{array}{l}\text { Spray coating } \\
\text { Current Method }\end{array}$ & $23^{\circ} \mathrm{C}, 50 \%$ & 4.4 \\
\hline $\begin{array}{l}\text { Cellulose nanofiber - } \\
\text { MMT (Closite 116) } \\
\text { Composite }\end{array}$ & $5 \%$ & $\begin{array}{l}\text { Spray coating } \\
\text { Current Method }\end{array}$ & $23^{\circ} \mathrm{C}, 50 \%$ & 5.5 \\
\hline $\begin{array}{c}\text { Cellulose nanofiber - MMT (Closite } \\
\mathrm{Na}++ \text { ) Composite }\end{array}$ & $23.1 \%$ & $\begin{array}{c}\text { Standard } \\
\text { Vacuum } \\
\text { Filtration }\end{array}$ & $23^{\circ} \mathrm{C}, 50 \%$ & $6.3 \pm 1.5$ \\
\hline Cellulose nanofiber(CNF)-clay & $25 \mathrm{wt} \%$ & $\begin{array}{l}\text { Vacuum filtration } \\
\text { followed by vacuum } \\
\text { oven dry }\end{array}$ & $23^{\circ} \mathrm{C}, 50 \%$ & 1800000 \\
\hline $\begin{array}{l}\text { Cellulose foam with Tween } 80 \\
\text { surfactant-surface modified } \\
\text { montmorillonite }\end{array}$ & $2.5 \mathrm{wt} \%$ & $\begin{array}{c}\text { High shear } \\
\text { homogenization and } \\
\text { solvent casting }\end{array}$ & $20^{\circ} \mathrm{C}, 50 \%$ & 216000 \\
\hline $\begin{array}{c}\text { Trimethylammonium-modified } \\
\text { nanofibrillated cellulose and } \\
\text { layered silicate (TMA-NFC/Mica } \\
\text { R120) }\end{array}$ & $50 \mathrm{wt} \%$ & $\begin{array}{c}\text { High shear } \\
\text { homogenization } \\
\text { followed by pressure } \\
\text { filtration and vacuum } \\
\text { hot-pressing }\end{array}$ & $23^{\circ} \mathrm{C}, 85 \%$ & 2200 \\
\hline $\begin{array}{c}\text { Trimethylammonium-modified } \\
\text { nanofibrillated cellulose and } \\
\text { vermiculite (TMA- } \\
\text { NFC/Vermiculite) }\end{array}$ & $50 \mathrm{wt} \%$ & $\begin{array}{c}\text { High shear } \\
\text { homogenization } \\
\text { followed by pressure } \\
\text { filtration and vacuum } \\
\text { hot-pressing }\end{array}$ & $23^{\circ} \mathrm{C}, 85 \%$ & 1400 \\
\hline $\begin{array}{c}\text { Poly(vinyl alcohol) (PVA)- } \\
\text { Poly(acrylic acid) (PAA)-NFC- } \\
\text { sodium montmorillonite (MMT) }\end{array}$ & $50 \mathrm{wt} \%$ & Solvent casting & $23^{\circ} \mathrm{C}, 50 \%$ & 105 \\
\hline $\begin{array}{c}\text { Nanofibrillated cellulose (NFC) - } \\
\text { vermiculite (VER) }\end{array}$ & $20 \mathrm{wt} \%$ & $\begin{array}{l}24 \text { h mixing followed by } \\
\text { two high pressure } \\
\text { homogenization; and } \\
\text { then solvent } \\
\text { evaporation }\end{array}$ & $23^{\circ} \mathrm{C}, 50 \%$ & 60 \\
\hline $\begin{array}{l}\text { Bacterial cellulose (BC)- } \\
\text { unmodified MMT }\end{array}$ & 9 wt $\%$ & $\begin{array}{l}\text { In-situ assembling or } \\
\text { one-step biosynthesis } \\
\text { process }\end{array}$ & $25^{\circ} \mathrm{C}, 50 \%$ & 53 \\
\hline $\begin{array}{l}\text { Low methoxyl pectin (LMP)- } \\
\text { carboxymethyl cellulose (CMC)- } \\
\text { MMT }\end{array}$ & $\begin{array}{l}4 \mathrm{wt} \% \\
\text { (LMP-CMC } \\
\text { ratio was } \\
10: 0 \text { ) }\end{array}$ & Solvent casting & $25^{\circ} \mathrm{C}, 50 \%$ & 29 \\
\hline $\begin{array}{c}\text { Cellulose nanofibrils (CNFs)- } \\
\text { mineral montmorillonite (MMT) }\end{array}$ & $32.5 \mathrm{wt} \%$ & Solvent casting & $23^{\circ} \mathrm{C}, 50 \%$ & 16 \\
\hline
\end{tabular}

WVP. The spraying of CNF-MMT suspension on a polished metal surface results in the product of a smooth composite which has considerbly smooth subtrate for the fabrication of printed electronic circuits. This rapid process builds a foundation for scalable opportunities in numerous advanced manufacturing settings and applications. The reduction of feedstock's cost and source of feedstock for production of cellulose nanofiber could make this spraying technology as a feasible process for developing cellulose nanofiber substrates [26].

\section{Novelty of this work}

The spray coated cellulose nanofiber-MMT nanocomposite can be a promising alternative barrier material for synthetic packaging and an eco friendly substrate for developing various functional material such as electronic devices. The formation of composite film via spray coating is very fast and the operation time for this methodlogy was less than a mintue when comparing to vaccum filtration which is a conventional method.

\section{Acknowledgement}

The use of the facilities of the Monash Centre for Electron Microscopy is acknowledged. I would like to sincerely thank Dr. Xi-Ya Fang for SEM for investigating the cross- sectional view of spray coated nanocomposites. I would like to thank my supervisors Associate Professor Warren Batchelor and Professor Gil Garnier, Department of Chemical Engineering, Monash University, Australia for supervision throughout conducting this research. I also thank to Mrs. Maisha Maliha for helped me in the fabrication of the nanocomposite sheet/films.

\section{Conflicts of Interest:}

In view of this submission the authors declare that there are no conflicts of interest.

\section{References}

1. Appendini, P. and J.H. Hotchkiss, Review of antimicrobial food packaging. Innovative Food Science \& Emerging Technologies, 2002, 3(2), 113-126.

2. Abitbol, T., et al., Nanocellulose, a tiny fiber with huge applications. Current Opinion in Biotechnology, 2016, 39, 76-88.

3. Ramos, M., A. Valdés, and M.C. Garrigós, Chapter 6 Multifunctional Applications of Nanocellulose-Based Nanocomposites, in Multifunctional Polymeric Nanocomposites Based on Cellulosic Reinforcements. 2016, William Andrew Publishing. 177-204.

4. Beneventi, D., E. Zeno, and D. Chaussy, Rapid nanopaper production by spray deposition of concentrated 
microfibrillated cellulose slurries. Industrial Crops and Products, 2015, 72, 200-205.

5. Beneventi, D., et al., Highly Porous Paper Loading with Microfibrillated Cellulose by Spray Coating on Wet Substrates. Industrial \& Engineering Chemistry Research, 2014, 53(27), 10982-10989.

6. Beneventi, D., et al., Pilot-scale elaboration of graphite/microfibrillated cellulose anodes for Li-ion batteries by spray deposition on a forming paper sheet. Chemical Engineering Journal, 2014, 243, 372-379.

7. Varanasi, S. and W.J. Batchelor, Rapid preparation of cellulose nanofibre sheet. Cellulose, 2013, 20(1), 211-215.

8. Shimizu, M., et al., Hydrophobic, Ductile, and Transparent Nanocellulose Films with Quaternary Alkylammonium Carboxylates on Nanofibril Surfaces. Biomacromolecules, 2014, 15(11), 4320-4325.

9. Krol, L.F., et al., Microfibrillated cellulose-SiO2 composite nanopapers produced by spray deposition. Journal of Materials Science, 2015, 50(11), 4095-4103.

10. Raj, P., et al., Gel point as a measure of cellulose nanofibre quality and feedstock development with mechanical energy. Cellulose, 2016, 23(5), 3051-3064.

11. Shanmugam, K., et al., Rapid preparation of smooth nanocellulose films using spray coating. Cellulose, 2017: 24(7), 2669-2676.

12. Shanmugam, K., Spray coated nanocellulose filmsproduction, characterisation and applications. PhD Thesis , Monash University, Australia, 2019.

13. Svedström, Kirsi, Ingela Bjurhager, Aki Kallonen, Marko Peura, and Ritva Serimaa. Structure of oak wood from the Swedish warship Vasa revealed by X-ray scattering and microtomography, 2012, 355-363.

14. Garusinghe, U.M., et al., Nanocellulose-montmorillonite composites of low water vapour permeability. Colloids and Surfaces A: Physicochemical and Engineering Aspects, 2018, 540, 233-241.

15. Ward, W., et al., Gas barrier improvement using vermiculite and mica in polymer films. Journal of membrane science, 1991, 55(1-2), 173-180.

16. Shanmugam, K., et al., Flexible spray coating process for smooth nanocellulose film production. Cellulose, 2018; 25(3), 1725-1741.

17. Odom, I., $\mathrm{Na} / \mathrm{Ca}$ montmorillonite: properties and uses. Society of Mining Engineers Transactions, 1987. 282.

18. Kalia, S., et al., Cellulose-Based Bio- and Nanocomposites: A Review. International Journal of Polymer Science, 2011, 135.

19. Alexandre, B., et al., Water barrier properties of polyamide 12/montmorillonite nanocomposite membranes: Structure and volume fraction effects. Journal of Membrane Science, 2009, 328(1),186-204.

20. Azeredo, H.M.C.d., Nanocomposites for food packaging applications. Food Research International, 2009, 42(9): 1240-1253.

21. Shailesh, S., et al., Effect of interfacial pretreatment on the properties of montmorillonite/poly(vinyl alcohol) nanocomposites. Journal of Applied Polymer Science, 2015, 132(18).

22. Furukawa, Y., et al., Aggregation of montmorillonite and organic matter in aqueous media containing artificial seawater. Geochemical Transactions, 2009, 10, 2-2.

23. Torvinen, K., et al., Smooth and flexible filler-nanocellulose composite structure for printed electronics applications. Cellulose, 2012, 19(3), 821-829.

24. Shanmugam, K., et al., High-performance homogenized and spray coated nanofibrillated cellulose-montmorillonite barriers. Cellulose, 2020: 28 (1), 405 -416.

25. Shanmugam, K., et al., Engineering surface roughness of nanocellulose film via spraying to produce smooth substrates. Colloids and Surfaces A: Physicochemical and Engineering Aspects, 2020, 589, 124396.

26. Jonoobi, Mehdi, Aji P. Mathew, and Kristiina Oksman. Producing low-cost cellulose nanofiber from sludge as new source of raw materials. Industrial Crops and Products, 40, 2012, 232-238. 